\title{
CONTINUIDADE E RUPTURA NO PROCESSO DE CONSTITUIÇÃO PSÍQUICA
}

\author{
Claudia Amorim Garcia*
}

\section{RESUMO}

O trabalho se constitui numa discussão sobre o processo de constituição dos limites psíquicos em duas leituras contrastantes representadas por Andre Green e Donald Winnicott. Inicialmente apresentamos duas hipóteses sobre esta questão encontradas no texto freudiano, especificamente em 1930, que a nosso ver fundamentam os desenvolvimentos teóricos posteriores em Winnicott e Green. Então, a possibilidade de pensar a constituição psíquica a partir do postulado de uma indiferenciação primária, em Freud, se apresenta, em Winnicott, através do recurso ao paradoxo enquanto figura emblemática do processo de constituição psíquica. Por outro lado, a postulação freudiana sobre a ausência enquanto requisito fundamental da constituição da psique ressurge em Green sob a forma da exigência do trabalho do negativo, evento central na construção dos limites psíquicos.

Palavras-chave: limites psíquicos; paradoxo; trabalho do negativo; Green; Winnicott.

\section{Abstract}

\section{CONTINUITY AND DISCONTINUITY IN THE CONSTITUTION OF THE PSYCHE}

This article is a discussion about the constitution of psychic borders in Andre Green and Donald Winnicott. We initially discuss two main Freudian hypotheses presented in 1930 which seem to support Green's and Winnicott's later contributions on this topic. Hence, the Freudian postulation of a primary undifferentiation is further developed by Winnicott by means of the use of the paradox, emblematic of his understanding of the constitution of the psyche. On the other hand, Freud's hypothesis about the inevitability of an experience of absence at the onset of

* Phd em Psicologia Clínica (The Wright Institute, Berkeley); Professora Associada do Departamento de Psicologia da Pontifícia Universidade Católica do Rio de Janeiro (PUC-Rio); Membro efetivo do Círculo Psicanalítico do Rio de Janeiro. 
psychic limits reappears in Green's concept of the work of the negative, a central event in the constitution of the psyche.

Keywords: psychic limits; paradox; work of the negative; Green; Winnicott.

Atribuímos a atualidade incontestável da problemática dos limites psíquicos à sua pertinência ao campo de discussões sobre o que se convencionou chamar de novas patologias, principalmente aquelas que constituem o amplo espectro do que opto por denominar de estados limítrofes de analisibilidade (Green, 1975). Não há consenso terminológico na designação dessas estruturações psíquicas que tanto são consideradas como organizações que se situam entre a psicose e a neurose, principalmente nos limites da psicose, quanto estruturas relativamente autônomas e estáveis que se caracterizam pelo prejuízo na constituição dos limites psíquicos, o que interfere com a capacidade representacional e afeta drasticamente a possibilidade de investimento afetivo na medida em que a distinção eu-outro é apenas fragilmente estabelecida.

Identificamos em Stern, num texto de 1938, uma primeira aproximação do conceito de paciente limítrofe, logo seguida da postulação "personalidade como se” de Helene Deutsch (1942), mas é no bojo da produção psicanalítica anglosaxônica da década de 60 que esta questão passa a receber uma atenção especial, sendo desta época as primeiras contribuições relevantes de Winnicott ([1960] 1980), Searles (1965), Kernberg ([1967] 1975) e Balint ([1968] 1993). No entanto, foi principalmente a partir do início da década de 80 que especificamente a temática dos limites psíquicos, central na dinâmica destes pacientes, passou a ocupar um lugar de destaque na produção teórico-clínica psicanalítica, ainda que não tenha sido objeto de um interesse maior na França até recentemente, com a exceção, evidentemente, dos trabalhos de André Green. Entre nós este tema adquiriu relevância no debate psicanalítico principalmente a partir dos anos $90 \mathrm{e}$, neste sentido, vale lembrar as conferências que Green proferiu no Brasil, em 1986, mais tarde publicadas sob o título de Metapsicologia dos limites (Green, [1986a] 1990), nas quais o autor amplia o escopo da discussão sobre os estados-limite ao abordar o limite em si como uma categoria metapsicológica indispensável à compreensão clínica.

A problemática dos limites psíquicos foi, desde o início, muito cara à psicanálise, tendo atraído a atenção de Freud inúmeras vezes. Sua abrangência evidentemente ultrapassa o domínio da patologia já que esta questão se refere à própria constituição do psíquico, isto é, diz respeito à delimitação das fronteiras intrapsíquicas e intersubjetivas e ao estabelecimento das relações entre mundo 
interno e realidade externa, tarefa sempre inconclusa da qual, entretanto, os humanos parecem não conseguir se abster. Será, então, a partir da apresentação de algumas ideias de Freud sobre esta questão que passaremos, em seguida, a desenvolver o tema da constituição dos limites psíquicos fazendo uso das contribuições de Winnicott e Green, que discutem esta temática de maneiras distintas.

\section{SOBRE A ARTICULAÇÃO REALIDADE PSÍQUICA/REALIDADE EXTERNA EM FREUd}

O tema das relaçôes entre o subjetivo e o objetivo aparece no texto freudiano com frequência e de diferentes maneiras, dentre as quais se destacam a discussão sobre a articulação realidade psíquica/realidade material e as hipóteses sobre a constituição recíproca do eu ${ }^{1}$ e da realidade externa. A posição inicial explicitada em 1900 (1976) segundo a qual os sonhos são considerados representantes de uma realidade psíquica própria dos desejos inconscientes, que se diferencia da realidade material, é revista e ampliada em trabalhos posteriores nos quais esta distinção parece ser problematizada através da hipótese filogenética. Assim, tanto em "Totem e tabu" (Freud, [1913] 1974), na discussão final sobre a origem do sentimento de culpa e dos preceitos morais na neurose e nos povos primitivos, quanto na "Conferência introdutória XXIII" (Freud, [1916-1917] 1976), na postulação das cenas infantis sustentadas pelas fantasias originárias, a afirmativa freudiana sobre a irredutibilidade do psíquico é contrabalançada pela hipótese filogenética que aponta para o caráter factual histórico daquelas manifestações subjetivas. Então, a declaração inequívoca de que "no mundo das neuroses, a realidade psíquica é a realidade decisiva” (Freud, [1916-1917] 1976: 430) é complementada pela afirmativa segundo a qual as fantasias originárias representam um "acervo filogenético [...] e foram, em determinada época, ocorrências reais dos tempos primitivos da família humana" (Freud, [1916-1917] 1976: 433). Da mesma forma, a frase final de "Totem e tabu" - "no princípio foi o Ato" (Freud, [1913] 1974: 191) - parece se referir ao evento que funda, ao mesmo tempo, a realidade psíquica e a realidade material/histórica, já que "a realidade psíquica coincidiu no princípio com a realidade concreta” (Freud, [1913] 1974: 190). Fica, então, assim evidenciada a articulação inquestionável entre o psíquico e o histórico/material no texto freudiano, postulado que também sustenta suas formulações a respeito do processo de constituição do eu, numa linha de raciocínio da qual não participa a hipótese filogenética.

O objetivo do texto de 1911 é enunciado logo de saída: investigar a relação dos neuróticos e da humanidade em geral com a realidade aqui representada 
pelo princípio da realidade. De fato, a discussão que se segue sobre a existência dos princípios do prazer e da realidade e, principalmente, da transição entre eles constitui o eixo central do trabalho em que se dá uma primeira tentativa de discussão sobre o eu pautada no funcionamento dos dois princípios. É neste sentido que são postulados um eu prazer, direcionado para a obtenção do prazer e evitação do desprazer, e um eu realidade, que trabalha pelo que é útil e "resguarda-se de danos" (Freud, [1911] 1969: 283). Nada, entretanto, é dito sobre suas origens e destinos.

Em 1915 (1974), no texto sobre as pulsões, a questão é retomada e adquire uma maior complexidade com a introdução do eu realidade original, tributário da pulsão de autopreservação tão fundamental nos movimentos iniciais de distinção interno/externo já que é essencialmente através da motilidade, a serviço da autopreservação, que se dá uma primeira construção da externalidade. Além disto, neste momento primeiro essencialmente narcísico de constituição psíquica, em que o autoerotismo, representante do sexual, garante a satisfação pulsional incipiente, a partir do corpo próprio, é somente através da autopreservação que o eu realidade original "adquire objetos" (Freud, [1915] 1974: 157) do mundo externo. Sendo assim, os objetos da necessidade são os primeiros a serem "levados do mundo externo para o ego, a princípio, pelos instintos de autopreservação" (ibid.: 158). Logo, no entanto, sob a influência do princípio do prazer, se constitui o eu prazer purificado que, como efeito do prolongamento do investimento narcísico pelos pais, adia o estabelecimento do eu realidade definitiva mostrando, mais uma vez, que a ordem do sexual posterga a construção da relação com a realidade externa aqui entendida como princípio da realidade. Neste registro do eu prazer purificado são incorporados os objetos que possibilitam o prazer e expelido tudo aquilo que resulta em desprazer. O interno passa então a coincidir com o prazeroso e o externo com o que é desprazeroso mas também estranho, um resíduo do mundo externo que não foi incorporado como prazeroso.

Curiosamente, o eu da realidade não consta do trabalho de 1915 (1974), mas ocupa lugar de destaque na "Negativa" ([1925] 1976), na qual aparece sob a forma de eu realidade definitivo encarregado do julgamento de existência, enquanto que o julgamento de atribuição permanece na alçada do eu prazer. A distinção entre o que é irreal, isto é, meramente representacional e subjetivo, constituindo o mundo interno, e aquilo que é real, isto é, representacional e externo, enquanto perceptivo, constitui o foco do trabalho no qual, portanto, a questão da construção da externalidade é ponto central. Duas afirmativas presentes neste texto de 1925 (1976) foram retomadas e ampliadas em 1930 e se mostram especi- 
almente relevantes para a discussão que desenvolveremos a respeito das contribuições de Winnicott e Green sobre a temática dos limites.

A primeira dessas afirmativas diz respeito à ausência inicial de diferenciação subjetivo/objetivo na origem do psíquico e se apresenta como uma novidade no texto freudiano. Esta ideia vai ser amplamente discutida no "Mal-estar" (Freud, [1930] 1974) não apenas através da consideração de um sentimento oceânico, que diria respeito à indiscriminação dentro/fora, mas também na postulação de uma indistinção eu/isso, que se oporia à aparência enganosa de uma unidade egoica independente. A indiferenciação intrapsíquica é um postulado freudiano antigo, mas a ideia de uma ausência de limites interno/externo é pela primeira vez apresentada neste texto sob a forma de um sentimento oceânico, resíduo da experiência de inclusão totalizadora que caracterizaria os momentos iniciais da constituição psíquica. "Originalmente o ego inclui tudo, posteriormente separa de si mesmo um mundo externo" (Freud, [1930] 1974: 85). Esta hipótese freudiana acerca da indiferenciação inicial remete às ideias de Winnicott sobre a relação inicial do bebê com seu entorno, apesar de também delas se diferenciar na medida em que não faz jus ao seu caráter paradoxal.

A segunda das afirmativas presentes na "Negativa" (Freud, [1925] 1976), por outro lado, vai nos aproximar das postulaçôes greenianas. Nela Freud postula que a perda de objetos de satisfação é condição sine qua non para que se dê o teste de realidade, isto é, para que o objeto da representação seja reencontrado lá fora, na realidade externa, que desta maneira vai se construindo. No texto do "Mal-estar" (Freud, [1930] 1974) esta questão é retomada mostrando que a externalidade já não resulta apenas da expulsão do desprazeroso mas é também efeito da constatação da falta do objeto que existe lá fora: "de tempos em tempos, outras fontes lhe fogem - entre as quais se destaca a mais desejada de todas, o seio da mãe -, só reaparecendo como resultado de seus gritos de socorro" (Freud, [1930] 1974: 84).

A ausência, portanto, é decisiva na construção da representação da realidade externa cujo aparecimento não se dá de forma imediata e automática, mas apenas como resposta a um chamado que remete ao que não está presente. A constatação de que o apelo é indispensável para que a necessidade seja atendida é fundamental para o rompimento do sentimento de inclusão totalizadora do eu e contribui para a formação de um primeiro limite interno/externo. É justamente esta formulação, reapropriada e resignificada, que norteia o argumento de Andre Green sobre a constituição das fronteiras psíquicas, principalmente na sua discussão sobre o trabalho do negativo. 
Então, Winnicott e Green, cada qual a sua maneira, fazem valer essas proposições freudianas em direções diferentes apresentando em comum a tendência a colocar em questão a possibilidade de uma constituição demarcada e nítida dos limites psíquicos que parece dominante no texto freudiano, com algumas poucas exceções. No entanto, compartilham com Freud do entendimento de que o processo de constituição psíquica se dá essencialmente como efeito da criação recíproca de um interior e de um exterior, constituindo-se, portanto, sempre num movimento de apropriação subjetiva.

\section{A CONTINUIDAde NA CONSTITUIÇÃo PSíQUiCA: WinNiCOTT E O PARADOXO MATURACIONAL}

O paradoxo é uma proposição composta de duas afirmativas incompatíveis e verdadeiras e sua origem se deu no campo da lógica formal (Roussillon, [1991] 2006). A importância do paradoxo no campo das teorias sobre o humano foi reconhecida pelo grupo de Palo Alto, nos Estados Unidos, que nos anos 50 se reuniu em torno de Gregory Bateson, antropólogo interessado em trazer as contribuições da cibernética para o campo das relações humanas e precursor no estudo das possibilidades terapêuticas do paradoxo. Mais tarde, e em continuidade com os trabalhos de Bateson, o Grupo de Palo Alto passou a desenvolver uma pesquisa sistemática sobre a comunicação humana nos seus aspectos semânticos, sintáticos e pragmáticos, com ênfase na pragmática da comunicação. Esta pesquisa foi relatada na Pragmática da comunicação humana, de 1967, publicação conjunta de Watzlawick, Beavin e Jackson que, a partir de seus estudos com famílias de pacientes esquizofrênicos, identificaram vários tipos de comunicação paradoxal. O Grupo de Palo Alto se tornou conhecido por suas contribuiçôes a respeito das injunções paradoxais esquizofrenizantes, tendo sempre marcado a importância do paradoxo para a patologia da comunicação, mas também dele se utilizado enquanto ferramenta terapêutica. A posição antipsicanalítica destes pesquisadores, no entanto, impediu que suas contribuiçôes pudessem ser apreciadas pela psicanálise. Roussillon ([1991] 2006), no seu rigoroso estudo sobre os paradoxos da psicanálise, reconhece a relevância das pesquisas do Grupo e apresenta uma cuidadosa análise critico-epistemológica dos teóricos de Palo Alto, enfatizando, principalmente, a contribuição de Bateson para a discussão sobre a relação entre o paradoxo e o jogo, questão que foi exaustivamente trabalhada por Winnicott, duas décadas depois. Nesta época Searles (1965), nos Estados Unidos, e mais tarde, na década de 70, na França, Recamier (1978) e Anzieu (1974; [1985] 1989) também se interessaram pela relevância clínica dos paradoxos, principalmente no 
seu aspecto patológico, dando assim continuidade, a partir de diferentes premissas teóricas, ao legado do Grupo de Palo Alto. Mas foi, sem dúvida alguma, com Winnicott que o paradoxo, no seu aspecto estruturante, se tornou objeto privilegiado da pesquisa teórico-clínica psicanalítica, apesar de não ter se constituído como conceito psicanalítico stricto sensu.

Com Winnicott o paradoxo adquire um valor essencialmente maturacional, e a experiência do paradoxo passa a ser considerada requisito fundamental para um desenvolvimento emocional saudável, como ele costumava dizer, embora possamos também considerar paradoxais algumas defesas discutidas no texto winnicottiano. Não encontramos, entretanto, uma teoria formal do paradoxo, em Winnicott, mas indicações esparsas ao longo de seu escritos, e contribuições de seus comentadores, nos permitem fazer algumas afirmações.

Apesar de a figura do paradoxo exemplificar magistralmente a posição de Winnicott acerca da relação entre realidade interna e mundo externo, cerne da problemática winnicottiana, é só a partir do final dos anos 50 que se consolida sua posição de destaque no texto winnicottiano. Neste sentido, é curioso verificar que na primeira versão do artigo "Objetos transicionais e fenômenos transicionais" (Winnicott, [1951] 1978) não consta o vocábulo paradoxo, apesar de esta noção já estar presente naquele texto através do termo ilusão (Caldwell, 2007). Assim, em 1951 (1978), Winnicott se refere à "existência de um valor positivo da ilusão" (Winnicott, [1951] 1978: 407) enquanto que em 1971 (1975) ele afirma que "o paradoxo aceito pode ter um valor positivo" (Winnicott, [1971] 1975: 30), o que sugere uma estreita proximidade semântica entre os dois termos, mas não justifica uma equivalência conceitual entre eles ${ }^{2}$.

Então, a ideia do paradoxo já permeava o pensamento de Winnicott mesmo antes de seu aparecimento formal, em 1958 (1980), no trabalho sobre a capacidade de estar só. Segundo Roussillon ([1991] 2006), uma primeira menção rápida ao paradoxo consta do texto de 1949 (1978) sobre a relação entre a mente e o psique-soma no qual Winnicott afirma que a mente não existe como uma entidade separada, apesar da insistência dos pacientes de localizá-la em algum lugar. Daí por diante inúmeras referências são feitas ao paradoxo enquanto uma experiência, sobretudo nos trabalhos que compóem a coletânea $O$ brincar $e$ a realidade, de 1971 (1975).

Antes de qualquer coisa o paradoxo winnicottiano se apresenta na forma de uma experiência que se caracteriza pela qualidade de transicionalidade e que, ao ser respeitada no seu caráter paradoxal, garante a continuidade interno/externo. Portanto, para que o paradoxo possa cumprir sua função de facilitar a sempre difícil transição entre a realidade interna e a externa, tarefa que se mantém perma- 
nentemente inacabada, é essencial que a pergunta sobre sua natureza nunca seja formulada. Assim, é indispensável que o paradoxo seja respeitado e não resolvido, o que exige a vigência de uma maternagem suficientemente boa que permita e sustente a situação paradoxal que se sofistica no decorrer do processo maturacional.

A experiência do paradoxo se complexifica ao longo do desenvolvimento emocional, sempre mantendo, no entanto, sua função precípua de assegurar uma continuidade que se dá na intersecção entre a ausência e a presença. É assim na ilusão de onipotência (Dias, 2003), que consiste na exigência paradoxal de que o mundo seja apresentado para ser inventado. $\mathrm{O}$ mesmo acontece com o objeto transicional cuja natureza paradoxal aponta justamente para a intersecção entre a criação e o encontro (Winnicott, [1971] 1975). Da mesma forma, a mãe que se faz ausente na presença do seu bebê permite-lhe a experiência paradoxal de estar só na presença de alguém (Winnicott, [1958] 1980). De maneira semelhante, a destruição do objeto subjetivo que possibilita a construção da externalidade só acontece quando o objeto sobrevive, o que configura, mais uma vez, um fenômeno paradoxal (Winnicott, [1969] 1975). Em todas essas situações paradoxais exemplares, é a existência de um meio ambiente silencioso, que não exige uma definição, que não se deixa perceber e não repudia e, portanto, que respeita o paradoxo sem exigir sua resolução, o que garante a eficácia da experiência do paradoxo. Talvez seja exatamente este o elemento que diferencia radicalmente o paradoxo winnicottiano das comunicações paradoxais esquizofrenizantes, estudadas pelo Grupo de Palo Alto, já que no caso delas o ambiente é intrusivo, aprisionante e exige a solução do paradoxo, provocando intensa angústia, que estaria na origem da esquizofrenia, segundo os pesquisadores norte-americanos. Diferentemente das injunçôes paradoxais esquizofrenizantes, as experiências paradoxais em Winnicott estão associadas a situações prazerosas de relaxamento, alívio, ou mesmo ausência de integração, já que ocorrem na área intermediária que "exist[e] como lugar de repouso para o indivíduo empenhado na perpétua tarefa humana de manter as realidades interna e externa separadas ainda que inter-relacionadas" (Winnicott, [1971] 1975: 15). Então, a tensão inerente à tarefa sempre precária de articular o dentro e o fora é aliviada com a experiência do paradoxo desde que nenhuma definição quanto a seu estatuto seja exigida, ou seja, desde que a dubiedade de sua natureza seja respeitada.

A temática do paradoxo winnicottiano é mais cuidadosamente desenvolvida nos artigos de O brincar e a realidade. "Uma exposição teórica", de 1971 (1975), e "A localização da experiência cultural", ainda de 1967 (1975), trabalhos que apresentam uma enorme complementaridade temático-conceitual centralizada em torno da questão da relação mundo interno/realidade externa, corporificada na 
experiência do paradoxo. A área intermediária da experiência está em continuidade com o brincar, que por sua vez tem um lugar e um tempo. Não faz parte nem da realidade interna nem do mundo externo, mas acontece num entre onde se dá um fazer que leva tempo (Winnicott, [1971] 1975). O brincar em si, independente do seu conteúdo, é importante e caracteriza uma experiência excitante e prazerosa, mas também extremamente precária porque justamente se dá neste espaço paradoxal que não é nem subjetivo nem pertence à realidade externa, objetivamente percebida.

Mas o brincar não é apenas o primeiro uso de uma possessão não-eu, isto é, de um objeto transicional. É também, e fundamentalmente, a utilização do primeiro símbolo da união/separação mãe-bebê que se dá no espaço potencial, locus por excelência de produção da cultura, sua legítima herdeira. Assim, a função paradoxal de encenar uma separação que é uma união, que garante a continuidade subjetivo/objetivo, é o que caracteriza a cultura enquanto encruzilhada entre a tradição e a inovação. A este respeito Winnicott afirma que "A integração entre a originalidade e a aceitação da tradição como base da inventividade parece-me apenas mais um exemplo, e um exemplo emocionante, da ação recíproca entre separação e união" (Winnicott, [1967] 1975: 138).

Então, a experiência cultural é mais uma expressão do caráter inequivocamente paradoxal da trajetória humana que atesta a impossibilidade de uma delimitação definitiva entre o mundo interno e a realidade externa.

Tudo indica, portanto, que a importância atribuída ao paradoxo durante todo o desenvolvimento maturacional, desde seu início no período caracterizado pela relação com o objeto subjetivo, quanto na transicionalidade, e até mesmo nas manifestações culturais, demonstra que, para Winnicott, a tentativa humana de delimitação interno/externo se constitui numa tarefa árdua e infindável, embora inevitável. Esse esforço é em grande parte minimizado pela existência de uma área intermediária de experiência, essencialmente paradoxal, onde se situam os objetos e fenômenos transicionais, que passa a ser habitada pela cultura. $\mathrm{O}$ paradoxo pode ser considerado como uma qualidade do que acontece nessa área de transição, num tempo e num espaço intermediários: um tempo entre uma primeira criação subjetiva e a construção de um símbolo, e um espaço entre o objeto subjetivo e a realidade objetivamente percebida. É, portanto, a partir de um entre transicional que se constroem o espaço e o limite (Davis \& Walbridge, [1981] 1982) que constituem o lugar onde vivemos (Winnicott, [1971] 1975), sempre em certa medida transicional e, portanto, paradoxal.

No argumento winnicottiano, o objeto enquanto transicional ocupa um lugar fundamental, apontando para a delimitação sempre precária entre o interno e 
o externo. Também em Green os destinos do objeto são cruciais na construção dos limites psíquicos, questão central na clínica dos estados limite.

\section{O NEGATIVO NA CONSTITUIÇÃO DOS LIMITES PSÍQUICOS}

A produção psicanalítica de Green se situa na encruzilhada teórica entre a teoria pulsional clássica e a teoria das relações objetais, caracterizando-se, portanto, pela discussão que articula os conceitos de pulsão e objeto no entendimento do psíquico. Para Green ([1986b] 1990) a pulsão não apenas revela o objeto mas também dele necessita, já que a satisfação pulsional exige o investimento objetal. A relação entre eles, portanto, é de absoluta complementaridade Assim, pulsão e objeto se determinam reciprocamente sem, no entanto, se confundirem. Na verdade, a distinção entre eles é condição sine qua non para o funcionamento psíquico, isto é, representacional, na leitura greeniana, já que a coalescência da pulsão com o objeto interfere na constituição dos limites psíquicos, resultando num prejuízo ao pensamento, característica dominante nos casos-limite. A compreensão dos destinos da relação pulsão/objeto requer a consideração do trabalho do negativo em seus aspectos estruturantes e patológicos, mas sempre como expressão da atividade de negação. Negativizar significa dizer não e, portanto, estabelecer limites que possibilitem a atividade representacional. $\mathrm{O}$ trabalho do negativo se dá, portanto, nos limites da representação (Duparc, [1996] 1997).

São muitas as acepções do termo negativo, que tanto pode significar oposto, implicando a consideração de um jogo de forças antagônicas, como pode se referir apenas a uma inversão neutra na qual o positivo seria seu inverso numa relação simétrica, não antagônica. É também à ausência, àquilo que não se faz presente mas que pode se encontrar num estado de latência, que o negativo nos remete. Finalmente, negativo também pode significar nada tanto enquanto pronome indefinido - "Eu nada sei sobre isto" - quanto na sua forma substantiva - "O nada faz parte da existência”. O sentido psicanalítico do termo articula as diferentes acepções, atribuindo ao negativo um significado bastante específico (Green, [1993] 1995). Deste modo, em psicanálise, o negativo se refere não apenas ao latente préconsciente ou recalcado, mas também ao oposto antagônico e ao nada nirvânico e, enquanto atividade psíquica, se faz representar pelo trabalho do negativo em suas diferentes manifestações, que abrangem um amplo espectro de fenômenos psíquicos marcados pela atividade negativizante. Neste sentido, a negação enquanto função lógica é uma expressão da ação do negativo enquanto evento psíquico que, por sua vez, abarca manifestações tão diversas quanto o recalque, a forclusão e a função desobjetalizante. 
Em 1920 (1976), ao apresentar sua segunda teoria pulsional, Freud deixou claro que a continuidade da vida psíquica depende da ação conjunta da pulsão de vida e da pulsão de morte nas suas tarefas precípuas de ligação e desligamento. Esta posição freudiana é desenvolvida por Green através da atribuição de funções diferenciadas para Eros e pulsão de morte. Enquanto a função objetalizante caracteriza a pulsão de vida no seu movimento de ligar e construir unidades cada vez maiores, a função desobjetalizante, própria da pulsão de morte, age no sentido da ruptura e do desligamento, isto é, da negação. É neste sentido que o trabalho do negativo se insere no escopo da função desobjetalizante, já que em suas diferentes manifestaçôes se apresenta sempre como uma forma de negação (Green, [1986c] 1995).

A questão do negativo surge no texto greeniano muito cedo, no seu trabalho sobre a metapsicologia da neurose obsessiva de 1967 (Green, 1967a) e no artigo sobre narcisismo primário, do mesmo ano (Green, [1967b] 1983) e mais tarde publicado na coletânea Narcisismo de vida. Narcisismo de morte (Green, 1983). É, no entanto, principalmente na década de 70, no bojo da discussão sobre a constituição dos limites psíquicos, que Green se adentra na investigação sobre o negativo. São deste período vários trabalhos clínicos que abordam a ação patológica do negativo, como o texto sobre a alucinação negativa do dedo cortado do Homem dos lobos (Green, [1977a] 1995) e o artigo sobre o conceito borderline (Green, [1977b] 1986), no qual é enfatizado o lugar central da cisão nos casos limite e seu efeito deletério sobre a capacidade representacional desses pacientes. Também é dessa época o clássico "O analista, a simbolização e a ausência na situação analítica”, de 1975, texto em que foi cunhada a expressão clínica do vazio para designar pacientes que se situam no limite de analisibilidade pelos sérios prejuízos ao pensamento que apresentam, efeito do fracasso no trabalho do negativo. Nos anos oitenta esta temática adquire finalmente um lugar central na produção teórica de André Green, transformando-se o trabalho do negativo em um de seus conceitos nodais, processo que culmina na publicação da coletânea Le travail du negatif, de 1993 (1995), composta de reedições e trabalhos inéditos.

Foi, então, a partir de seu interesse pela construção dos limites psíquicos, motivado fundamentalmente pela clínica dos casos-limite, que Green elaborou sua teoria sobre o trabalho do negativo explicitamente inaugurada com o artigo "O duplo limite", de 1982 (apud Garcia, 2007). Nele, a partir de releitura da Negativa (Freud, [1925] 1976), texto freudiano que aponta para a importância do trabalho do negativo na delimitação eu/não eu, são discutidos aspectos estruturantes do negativo na construção dos limites intra e interpsíquicos. Assim, a fronteira dentro/fora, resultante de um primeiro movimento de excorporação determinado 
pelo juízo de atribuição, se faz seguir pelo recalcamento enquanto resposta àquilo que retorna do exterior e é responsável pela divisão ics/cs. Dá-se, então, a alucinação negativa do seio necessária à constituição de um espaço psíquico que pode, então, ser habitado pelas representaçôes e abre caminho para a emergência da negação, representante do recalque no campo da linguagem.

Ainda na década de 80 a temática dos limites e o lugar central que é atribuído ao trabalho do negativo foram amplamente discutidos nas conferências proferidas no Brasil. A partir da definição de quatro territórios - somático, psíquico inconsciente, psíquico consciente e real/social - é então lançada a hipótese, de matiz claramente winnicottiano, de que o psiquismo se constitui da combinação desses territórios, sendo, portanto, uma "gigantesca formação intermediária no diálogo entre o corpo e o mundo” (Green, [1986a] 1990: 51). A psique enquanto um território limite, portanto. Pois bem, o trabalho do negativo se dá justamente nas barreiras entre os territórios que constituem o psiquismo e se apresenta sob a forma de mecanismos de defesa primários, a saber, o recalque, a cisão, a negativa e a forclusão (Green, [1986a] 1990). Estas diferentes formas de dizer não, função princeps do trabalho do negativo, são cruciais na delimitação dos espaços psíquicos, mas é principalmente na sua inflexão sobre o objeto primário que o trabalho do negativo adquire toda sua enorme importância para a construção dos limites interno/externo.

A postulação greeniana sobre os destinos do objeto absolutamente necessário $^{3}$ (Green, [1988] 1995) decorre de sua discussão crítica a respeito da importância das vicissitudes objetais no processo de constituição psíquica e foi motivada pela experiência clínica com os estados limite, denominação pouco específica que abarca uma miríade de pacientes que apresentam em comum uma capacidade representacional prejudicada, indicativa de sua condição borderline (Figueiredo, 2003). Assim, os impasses clínicos encontrados no manejo destes pacientes, que constituem a assim denominada clínica do vazio (Green, 1975), atestam a centralidade do objeto na dinâmica limítrofe e apontam inequivocamente para a insuficiência elucidativa da abordagem exclusivamente pulsional, sem no entanto minimizar sua importância, principalmente no que diz respeito à função negativizante desempenhada pelo trabalho do negativo enquanto manifestação pulsional.

De fato, as formulações sobre os destinos do objeto primário, em Green, se sustentam em pelo menos dois pressupostos. O primeiro deles diz respeito à indispensabilidade da consideração do pulsional não apenas enquanto investimento objetal, mas também, e principalmente, enquanto função de negação realizada pelo trabalho do negativo, primordial no processo de apagamento do obje- 
to absolutamente necessário. $\mathrm{O}$ segundo pressuposto aponta a importância central do ambiente na sua função continente mas também enquanto objeto falível, e portanto não absoluto, que assim se mostra susceptível de ser apagado. Denotando, claramente, a marca winnicottiana de sua argumentação, Green se refere à importância do ambiente que acolhe o que resulta da excorporação ${ }^{4}$ e resiste aos ataques sem retaliação (Green, [1986c] 1995), permitindo a constituição da externalidade, isto é, dos limites eu/não-eu (Winnicott, [1969] 1975). Apesar de não ser ainda percebida como tal, é, então, a presença constante e fidedigna do objeto na realidade externa - o que inclui necessariamente sua capacidade de ser falível - que possibilita sua ausência enquanto esquecimento, situação que, presidida pelo trabalho do negativo, encena magistralmente o jogo de presença-ausência que fundamenta todo o processo. Pulsão e ambiente, numa ação conjunta, possibilitam, portanto, o necessário esquecimento do objeto primário absolutamente necessário e as consequências daí decorrentes, indispensáveis ao funcionamento psíquico, dentre as quais a constituição das fronteiras psíquicas ocupa lugar de destaque. De fato, o apagamento do objeto primário e sua apropriação sob forma de um vazio estruturante (Green, [1988] 1995) dão lugar aos objetos substitutos e à capacidade representacional, evidenciando a constituição dos limites psíquicos e permitindo a emergência do desejo. Este desfecho esperado, no entanto, não ocorre nos casos-limite, que evidenciam, por outro lado, um desvio na função do objeto, que ao invés de se mostrar falível se apresenta como absoluto e onipresente, indicando a insuficiência da função negativizante.

De fato, a clínica do vazio é testemunha eloquente da falência do trabalho do negativo na lida com o objeto absolutamente necessário (Green, 1975, [1988] 1995) e evidencia a onipresença do objeto absolutamente necessário que não se deixou esquecer. Foi a constatação clínica de intensas angústias de separação e ataques sistemáticos ao enquadre analítico que resultou na hipótese de que estes pacientes estavam submetidos à presença excessiva do objeto primário que não se deixou apagar mas se amalgamou com a pulsão (Green, [1988] 1995), tornandoa ainda mais intolerável. Nestes casos em que a ausência enquanto presença em potencial não se constituiu, a separação eu/não-eu se encontra seriamente ameaçada, o pensamento prejudicado e as atuações dominam o cenário clínico.

O papel crucial atribuído ao trabalho do negativo na construção das fronteiras psíquicas atesta a importância da descontinuidade, representada pela negação, na constituição psíquica. $\mathrm{Na}$ argumentação greeniana, portanto, é fundamental a função realizada pelo trabalho do negativo na delimitação dos limites externointerno, o que se realiza não apenas através dos diferentes mecanismos de defesa, amplamente caracterizados pela negação, mas também, e principalmente, pela 
ação de apagamento do objeto absolutamente necessário. As diversas manifestações do negativo, que permitem a ausência enquanto presença em potencial, são requisitos básicos que garantem não apenas a possibilidade de separação eu/outro, mas também a condição desejante e a vigência do pensamento.

\section{Conclusão}

Concluindo... Com Winnicott o postulado fundamental da continuidade subjetivo/objetivo se apresenta essencialmente na experiência fundante do paradoxo, que assegura uma distinção sempre muito precária entre a realidade externa e o mundo interno. Green, por outro lado, defende a exigência do trabalho do negativo responsável pelo apagamento do objeto primário, condição necessária e essencial que possibilita a constituição das fronteiras psíquicas enquanto duplo limite interno e externo. Se uma primeira leitura destes autores ressalta principalmente as diferenças entre eles, uma aproximação mais cuidadosa sugere, no entanto, que apesar de se situarem, de fato, em campos teóricos diversos, compartilham da apreciação pelo uso do paradoxo na construção de suas posições, marca registrada do pensamento winnicottiano mas nem sempre claramente discernível no texto greeniano.

Neste sentido, encontramos em Green inúmeros exemplos do uso argumentativo do paradoxo, principalmente no que diz respeito à relação pulsão/objeto. Assim, o objeto revela e estimula a pulsão, tendo, no entanto, que dela se proteger. Do mesmo modo, o objeto adquire a qualidade de excessivo justamente porque falta (Green, [1988] 1995). Em suma, a função do objeto é fundamentalmente paradoxal na medida em que estimula e contém, limita a pulsão. Mas é também, e principalmente no que se relaciona à própria categoria de limite, entendido como território permeável e flexível onde acontecem fenômenos (Green, [1986a] 1990), numa alusão evidente ao conceito de espaço transicional winnicottiano, que o emprego do paradoxo se torna mais evidente. Assim, a afirmativa "Não temos limites porque temos objetos e temos limite porque temos objetos" (Green, [1986a] 1995: 76-7) me parece sintetizar eloquentemente sua posição a respeito não apenas da construção dos limites mas também da constituição psíquica de uma maneira geral. Neste sentido, Green se apresenta como o winnicotttiano francês de que tanto se gabava ser (Green, [2000] 2003) e parece aderir, com características próprias, evidentemente, à tese da construção recíproca dos territórios eu/não-eu, cuja delimitação sempre precária se constitui em tarefa infinda a que se dedicam os humanos na sua trajetória existencial. 


\section{REFERÊNCIAS BIBLIOGRÁFICAS}

Anzieu, D. (1974). Le moi-peau. Nouvelle Revue de Psychanalyse, 8, 195-209. - (1985/1989). O eu-pele. São Paulo: Casa do Psicólogo.

Balint, M. (1968/1993). A falha básica. Aspectos terapêuticos da regressão. Porto Alegre: Artes Médicas.

Cadwell, L. (2007). Do objeto ao espaço e a natureza desta transição. Palestra realizada na Sociedade Psicanalítica do Rio de Janeiro. Mimeo.

Davis, M. \& Wallbridge, D. (1981/1982). Limite e espaço. Rio de Janeiro: Imago.

Dias, E. O. (2003). A teoria do amadurecimento de D. W. Winnicott. Rio de Janeiro: Imago.

Deutsch, H. (1942). Some forms of emotional disturbances and their relationship to schizophrenia. Psychoanalytical Quarterly, 11, 301-321.

Duparc, F. (1996/1997). André Green. Paris: PUF.

Figueiredo, L. C. (2003). Elementos para a clínica contemporânea. São Paulo: Escuta.

Freud, S. (1900/1976). A interpretação de sonhos. Obras completas, ESB, v. IV e V. Rio de Janeiro: Imago.

. (1911/1969). Formulaçôes sobre os dois princípios do funcionamento mental.

Obras completas, ESB, v. XII. Rio de Janeiro: Imago.

- (1913/1974). Totem e tabu. Obras completas, ESB, v. XIII. Rio de Janeiro: Imago.

- (1915/1974). Os instintos e suas vicissitudes. Obras Completas, ESB, v. XIV. Rio de Janeiro: Imago.

- (1916-1917/1976). Conferências introdutórias sobre psicanálise. Parte III. Obras completas, ESB, v. XVI. Rio de Janeiro: Imago.

- (1920/1976). Além do princípio do prazer. Obras completas, ESB, v. XVIII. Rio de Janeiro: Imago.

- (1925/1976). A negativa. Obras completas, ESB, v. XIX. Rio de Janeiro: Imago.

—. (1930/1974). O mal-estar na civilização. Obras completas, ESB, v. XXI. Rio de Janeiro: Imago.

Garcia, C. A (2007). Os estados limite e o trabalho do negativo; uma contribuição de A. Green para a clínica contemporânea. Mal-estar e subjetividade, 7 (1), 123-135.

Green, A. (1967a). Métapsychologie de la névrose obsessionnelle. Revue française de psychanalyse, 31 (4), 629-646.

—. (1967b/1983). Le narcissisme primaire: structure ou état? Em Narcissisme de vie. Narcissisme de mort (pp. 80-132). Paris: Les Éditions de Minuit.

. (1975). The analyst, symbolization and absence in the analytic setting (On changes in analytic practice and analytic experience). International Journal of Psychoanalysis, 56, 1-22. 
. (1977a/1995). La alucinación negativa. Em El trabajo de lo negativo (pp. 379385). Buenos Aires: Amorrortu editores. . (1977b/1986). The borderline concept. Em On private madness (pp. 60-83). Madison: International Universities Press. - (1983). Narcissisme de vie. Narcissisme de mort. Paris: Éditions de Minuit. - (1986a/1990). Conferências brasileiras de André Green. Metapsicologia dos limites. Rio de Janeiro: Imago.

. (1986b/1988). Pulsão de morte, narcisismo negativo, função desobjetalizante. Em A pulsão de morte (pp. 57-68). São Paulo: Escuta.

- (1986c/1995). El trabajo de lo negativo. Em El trabajo de lo negativo (pp. 371378). Buenos Aires: Amorrortu.

- (1988/1995). Seminário sobre el trabajo de lo negativo. Em El trabajo de lo negativo (pp. 386-392). Buenos Aires: Amorrortu.

- (1993/1995). El trabajo de lo negativo. Buenos Aires: Amorrortu.

-. (2000/2003). André Green e a fundação Squiggle. São Paulo: Roca.

Kernberg, O. (1967/1975). Borderline personality organization. Em Borderline conditions and pathological narcissism (pp. 3-47). New York: Jason Aronson.

Recamier, P.-C. (1978). Les paradoxes des schizophrènes. Revue Française de Psychanalyse, 42 (5-6), 871-885.

Roussillon, R. (1991/2006). Paradoxos e situaçôes limite da psicanálise. Vale dos Sinos: Editora Unisinos.

Searles, H. (1965). Collected papers on schizophrenia and related subjects. New York: The International Universities Press.

Stern, A. (1938). Investigação psicanalítica e a terapia do grupo das neuroses limítrofes. Revista Latinoamericana de Psicopatologia Fundamental, 2 (1), 159-166.

Watzlawick, P.; Beavin, J. H. \& Jackson, D. D. (1967). Pragmatics of human communication. New York: Norton \& Company.

Winnicott, D. (1949/1978). A mente e sua relação com o psique-soma. Em Textos selecionados. Da pediatria à psicanálise (pp. 409-426). Rio de Janeiro: Livraria Francisco Alves. - (1951/1978). Objetos transicionais e fenômenos transicionais. Em Textos selecionados. Da pediatria à psicanálise (pp. 389-408). Rio de Janeiro: Livraria Francisco Alves.

. (1958/1980). The capacity to be alone. Em The maturational processes and the facilitating environment (pp. 29-36). New York: International Universities Press. - (1960/1980). Ego distortions in terms of true and false self. Em The maturational processes and the facilitating environment (pp. 140-152). New York: International Universities Press. 
(1967/1975). A localização da experiência cultural. Em O brincar e a realidade (pp. 133-143). Rio de Janeiro: Imago.

- (1969/1975). O uso de um objeto e relacionamento através de identificações.

Em $O$ brincar e a realidade (pp. 121-131). Rio de Janeiro: Imago.

- (1971/1975). Objetos e fenômenos transicionais. Em O brincar e a realidade

(pp. 13-44). Rio de Janeiro: Imago.

\section{Notas}

1 Optamos por utilizar o vocábulo eu ao longo do texto, preservando, no entanto, nas citações o vocábulo ego como consta na Edição Standard Brasileira publicada pela Imago.

2 É interessante observar também que o texto de 1951 (1978), do qual não consta o vocábulo paradoxo, contém, por outro lado, uma discussão sobre o objeto fetiche, ausente das versôes posteriores, o que parece apontar para um duplo movimento que então se anunciava no texto winnicottiano representado por um gradual distanciamento de temas tipicamente freudianos e uma aproximação da temática que viria a se constituir como centro da problemática winnicottiana.

3 Termo evocativo da expressão winnicottiana ambiente suficientemente bom e utilizado por Green ([1988] 1995) para designar o objeto primário neste texto que, de resto, parece bastante inspirado nas contribuições do autor inglês.

4 Green denomina de excorporação um tipo muito primitivo de expulsão, expressão inequívoca das moções pulsionais orais, anterior à projeção, que não supõe a existência de um objeto que possa acolher aquilo que foi expulso, mas apenas de um espaço onde desaparece o resultado da excorporação (Green, [1986c], 1995).

Recebido em 05 de janeiro de 2009

Aceito para publicação em 09 de março de 2009 